\title{
$B R A F$ V600E mutation in papillary thyroid cancer is correlated with adverse clinicopathological features but not with iodine exposure
}

\author{
Serhat Özçelik', Rifat Bircan², Şükran Sarıkaya ${ }^{3}$, Aylin E. Gul ${ }^{3}$, Büşra Aydın², Melike Özçelik', \\ Mehmet Çelik', Akın Dayan ${ }^{1}$, Yasemin Tütüncü ${ }^{1}$, Hasret Cengiz' ${ }^{1}$, Nimet Karadayı ${ }^{3}$, Hülya Ilıksu Gözü ${ }^{5}$ \\ ${ }^{1}$ Endocrinology and Metabolism Section, Haydarpaşa Education and Training Hospital, Istanbul, Turkey \\ ${ }^{2}$ Department of Molecular Biology \& Genetics, Arts and Sciences Faculty, Namık Kemal University, Tekirdağ, Turkey \\ ${ }^{3}$ Department of Pathology, Kartal Dr. Lütfi Kırdar Education and Training Hospital, Istanbul, Turkey \\ ${ }^{4}$ Department of Medical Oncology, Kartal Dr. Lütfi Kırdar Education and Training Hospital, Istanbul, Turkey \\ ${ }^{5}$ Department of Endocrinology and Metabolism, Marmara University, School of Medicine, Istanbul, Turkey
}

\begin{abstract}
Introduction: $B R A F^{V 600 E}$ activating mutation is the most frequent genetic abnormality in the pathogenesis of papillary thyroid carcinoma. We aimed to evaluate the association between $B R A F^{V 600 E}$ mutation and well-established prognostic clinicopathological characteristics as well as iodine exposure.

Material and methods: From 2000 to 2012, the data of PTC patients admitted to Dr. Lutfi Kirdar Kartal Education and Research Hospital in Turkey were reviewed retrospectively. Clinicopathological parameters were collected. $B R A F^{V 600 E}$ mutation was analysed by DNA sequencing method in tumour specimens. We hypothesised that $B R A F^{V 600 E}$ mutation prevalence is positively correlated with prolonged iodine exposure and expected to be higher in the second half of the recruitment period due to the increment in time spent from the iodisation process of the table salt in our country. Thus, iodine exposure was categorised as short-term (2000-2006) and long-term (2006-2012).

Results: A total of 197 patients were accrued. The study population predominantly consisted of conventional variant. A statistically significant relationship was observed between $B R A F^{V 600 E}$ mutation presence and age $(p=0.03)$, conventional variant PTC $(p=0.00002)$, T4 stage $(\mathrm{p}=0.002)$, vascular invasion $(\mathrm{p}=0.036)$, thyroid capsule invasion $(\mathrm{p}<0.00001)$, extrathyroidal tissue invasion $(\mathrm{p}<0.00001)$, and lymph node metastasis $(\mathrm{p}<0.00001)$. When categorised as long-term and short-term, iodine exposure was not statistically significantly related with $B R A F^{V 600 E}$ mutation; however, there were far more PTC cases in the long-term group (86.3\% vs. $13.7 \%$ ).

Conclusion: We revealed that $B R A F^{V 600 E}$ mutation is associated with adverse clinicopathological parameters. There appeared to be no relation between long-term iodine exposure and $B R A F^{V 600 E}$. (Endokrynol Pol 2019; 70 (5): 401-408)
\end{abstract}

Key words: papillary thyroid cancer; BRAF V600E; iodine

\section{Introduction}

Thyroid carcinoma is the most frequent type of endocrine-borne malignancies. Papillary thyroid carcinoma (PTC) and follicular thyroid carcinoma (FTC), which are derived from follicular cells and C-cell-derived medullary thyroid carcinoma, are the common subtypes. Anaplastic type is the rarest variant and is highly aggressive [1].

Differentiated thyroid carcinomas, PTC and FTC, are slow-growing cancers. Early-stage disease can be treated successfully with surgical excision. Patients with disseminated disease eventually die from their cancer, although the majority survive for years, which is an uncommon circumstance for many other advanced-stage malignancies.
An understanding of thyroid cancer pathogenesis remains critical for the prevention of the disease occurrence and for the development of targeted therapies directed against the causative pathway in the care of patients with advanced disease. Contributory genetic abnormalities have been defined to cause different subtypes of thyroid cancer. Frequent genetic abnormalities associated with PTC are the BRAF activating mutations, fusion oncogene RET/PTC, and NTRK rearrangements. BRAF V600E activating mutation, which occurs in $29-83 \%$ of tumours, is the most common mutation in PTC. BRAF is the downstream target of RAS in the mitogen-activated protein kinase (MAPK) signalling pathway. Following activation, RAF interacts with MEK and initiates phosphorylation of ERK kinase leading its activation. Activated ERK mediates the transcription 
of many genes, which promotes cellular growth and survival [2-5].

Radiation exposure and iodine excess are the best-known predisposing factors for the development of PTC $[6,7]$. There is some evidence that high iodine exposure may be a driver event for transforming $B R A F$ to a constitutively active state [7]. In Turkey, iodisation of table salt was practised in 1999 and fully carried out in 2002 [8-10]. Duration of time from the iodisation process may be an indirect measure of iodine exposure.

Extensive data suggest that $B R A F^{V 600 E}$ mutation is associated with a poorer prognosis compared to PTC without harbouring the $B R A F^{V 600 E}$ mutation. It appears to be associated with increased risk of extrathyroidal tumour extension, lymph node metastases, and recurrence [7]. In this study, we aimed to describe the relation of iodine exposure, if any, as well as the clinicopathological factors with $B R A F^{V 600 E}$ mutation.

\section{Material and methods}

\section{Study oversight}

This study was conducted in compliance with the ethical principles according to the Declaration of Helsinki, and it was approved by the local Institutional Review Board (April 8, 2014). Data of PTC patients admitted to Dr. Lutfi Kirdar Kartal Education and Research Hospital were reviewed retrospectively. A total of 197 patients (159 females and 38 males; median age 46 , range $17-86$ years) with PTC were screened for $B R A F^{V 600 E}$ mutation in this study from October 2000 to October 2012. Other clinicopathological features including PTC variant, tumour size, T stage, necrosis, calcification, vascular invasion, tumour capsule status and invasion, extrathyroidal invasion, multicentricity, and concomitant pathology in thyroid tissue were collected.

Trials conducted in an effort to define the iodine status in the Turkish population, with the use of urinary iodine excretion, are presented in Table I. Urinary iodine excretion was not evaluated in our study. Using the national studies as the basis for the iodine status of the study population, we principally aimed to look for the concept of relative increment in iodine exposure [8-11]. We hypothesised that $B R A F^{V 600 E}$ mutation prevalence is positively correlated with increasing iodine exposure and is expected to be higher in the second half of the recruitment period (2006 to 2012) due to the increment in exposure time spent from the iodisation process of table salt in our country. Thus, iodine exposure was categorised as short-term (2000-2006) and long-term (2006-2012).

\section{Method \\ DNA Isolation}

Genomic DNA was extracted from 8-10 $\mu \mathrm{m}$ sections of formalinfixed and paraffin-embedded (FFPE) PTC tissue samples, starting with deparaffinisation using conventional xylene/ethanol treatment, one-hour incubation with proteinase $\mathrm{K}$, and subsequent DNA purification utilising the QIAampDNA FFPE tissue kit (Qiagen, USA) according to the manufacturer's instructions. Following the DNA isolation, DNA were archived at $-20^{\circ} \mathrm{C}$ in a freezer until the start of the study.

\section{PCR and DNA sequencing}

In order to detect the mutations at exon 15 of the BRAF gene, PCR was performed with the following forward and reverse primers as described by Qu K. et al. (2013): BRAF 15F, 5'-CCTAAACTCTTCATAATGCTTGCT-3'; and BRAF15R, 5'-AGTAACTCAGCAGCATCTCAGG-3' [12].

Briefly, PCR was performed in a $50 \mathrm{~mL}$ volume containing 50 to $100 \mathrm{ng}$ of genomic DNA; $20 \mathrm{pmol} / \mathrm{L}$ forward and $20 \mathrm{pmol} / \mathrm{L}$ reverse primers; HotStarTaq Master Mix (Qiagen, USA) including HotStarTaq DNA Polymerase (2.5 U), PCR Buffer (with $1.5 \mathrm{mM} \mathrm{MgCl}_{2}$ ), and $200 \mu \mathrm{M}$ each dNTP in final reaction volume. The PCR amplification was carried out in a Proflex thermocycler (ABI, USA) under the following conditions: one cycle at $95^{\circ} \mathrm{C}$ for 15 minutes; 40 cycles at $94^{\circ} \mathrm{C}$ for 30 seconds, $56^{\circ} \mathrm{C}$ for 30 seconds, and $72^{\circ} \mathrm{C}$ for 30 seconds; and a final extension step at $72^{\circ} \mathrm{C}$ for 10 minutes. Amplified PCR products were purified by using the PEG precipitation method as described by Rosenthal et al. (1993) [13]. The purified PCR products were sequenced utilising DTCS quick start kit (Beckman Coulter, USA). The sequencing reaction was carried out in a Proflex thermocycler at $96^{\circ} \mathrm{C}$ for $20 \mathrm{~s}, 50^{\circ} \mathrm{C}$ for $20 \mathrm{~s}$, and $60^{\circ} \mathrm{C}$ for four minutes, according to the manufacturer's manual. Sequence analysis was performed on the automatic DNA sequencer (Beckman Coulter Genome Lab GeXP Genetic Analysis System, USA). DNA sequences and chromatograms obtained were examined by using the Genome Lab GeXP Genetic Analysis System Version 10.2 DNA sequencing program (Beckman Coulter, USA).

\section{Statistical analysis}

All statistical analyses were carried out using SPSS 17.0 version (IBM Corp., Armonk, NY, USA). Characteristics of patients were evaluated with descriptive analysis. Chi-squared test and Fisher's exact test were used in order to compare the clinicopathological features as well as the iodine exposure status, between $B R A F^{V 600 E}$-positive and -negative subgroups. $\mathrm{P}$ values below 0.05 were accepted as statistically significant.

Table I. An overview of the iodine status screening trials in the Turkish population

\begin{tabular}{llcc}
\hline & Screening size & Study population (number) & Median UIC $[\mu \mathrm{g} / \mathrm{L}]$ \\
\hline $1997-1999$ & National (20 regions) & 5.948 & $36 \mu \mathrm{g} / \mathrm{L}$ \\
\hline $2002^{*}$ & National (20 regions) & 4.128 & $53 \mu \mathrm{g} / \mathrm{L}$ \\
\hline $2002^{* *}$ & National (10 regions) & 7.006 & $87,5 \mu \mathrm{g} / \mathrm{L}$ \\
\hline $2002^{* * *}$ & National (30 regions) & 11.134 & $75 \mu \mathrm{g} / \mathrm{L}$ \\
\hline $2007^{* * *}$ & National (30 regions) & 2.280 & $130 \mu \mathrm{g} / \mathrm{L}$ \\
\hline
\end{tabular}

*Follow-up studies of 1997-99 screening in 2002 (same 20 regions); ${ }^{* * 10}$ new regions screened in 2002 with unknown previous status; ${ }^{* * *}$ Total results of all 2002 screening (30 regions); ${ }^{* * *}$ Follow-up studies of 2002 screening in 2007; UIC — urinary iodine concentrations 


\section{Results}

\section{Patient characteristics}

A total of 197 patients with PTC were screened for BRAF V600E mutation in this study. Characteristics of patients are summarised in Table II. Conventional variant $(57.4 \%)$ was the predominant variant, followed by follicular $(33.5 \%)$ and oncocytic (9.1\%) variants. Tumour size ranged from 0.1 to $8 \mathrm{~cm}$ with a median size of 0.9 $\mathrm{cm}$. Microcarcinoma slightly dominated the samples with a ratio of $53.6 \%$. According to the eighth pTNM staging, 118 patients $(60.1 \%)$ had T1, 31 patients $(15.7 \%)$ T2, 27 patients (13.7\%) T3, and 21 patients (10.5\%) had T4 tumours. Extratumoural thyroid tissue consisted of diffuse hyperplasia (30.4\%), nodular adenomatous hyperplasia (24.3\%), nodular hyperplasia (19.8\%), lymphocytic thyroiditis (17.8\%), and multinodular adenomatous hyperplasia (14.7\%) with decreasing frequency. One or more condition/s might have been seen in one extratumoural tissue sample. Most of the tumours were limited to thyroid tissue, with only $17.7 \%$ having extrathyroidal tissue invasion and $7.6 \%$ exhibiting lymph node metastasis. Of 35 patients with extrathyroidal tissue invasion, $14(40 \%)$ had minor and $21(60 \%)$ had gross spread. While calcification status (45.2\% present, $54.8 \%$ absent) was almost evenly shared by samples, the presence of necrosis (1.5\%) and vascular invasion $(5.1 \%)$ were considerably low.

\section{BRAFV600E mutation}

$B R A F^{V 600 E}$ mutation frequency was found to be $22.8 \%$ (45/197) in this study. Association of $B R A F^{V 600 E}$ mutation with clinical and pathological parameters is detailed in Table III. A statistically significant relationship was observed between BRAF ${ }^{V 600 E}$ mutation presence and conventional variant PTC $(\mathrm{p}=0.00002), \mathrm{T} 4$ stage $(\mathrm{p}=0.002)$, vascular invasion $(\mathrm{p}=0.036)$, thyroid capsule invasion $(\mathrm{p}<0.00001)$, extrathyroidal tissue invasion $(\mathrm{p}<0.00001)$, and lymph node metastasis ( $\mathrm{p}<0.00001)$. Age, for the cut-off level, 45 ( $\left.7^{\text {th }} \mathrm{TNM}\right)$, was not significantly associated with $B R A F^{V 600 E}$ mutation whereas age, for the cut-off level of $55\left(8^{\text {th }} \mathrm{TMN}\right)$, was significantly associated with mutation status $(p=0.03)$. The extratumoural thyroid background, tumour necrosis and capsule formation were not significantly associated with $B R A F^{V 600 E}$ mutation. When grouped in two, iodine exposure, was not statistically significantly related with $B R A F^{V 600 E}$ mutation; however, there were more PTC cases in the long-term group compared to short-term ( $86.3 \%$ vs. $13.7 \%)$.

\section{Rare BRAF mutations}

Along with $B R A F^{V 600 E}$ mutation, $B R A F^{F 583 Y}, B R A F^{F 595 L}$, and $B R A F^{V 600 V}$ were also detected in the study group.
Table II. Clinicopathological features of patients

\begin{tabular}{|c|c|c|}
\hline & & $\mathbf{N}(\%)$ \\
\hline \multirow{2}{*}{ Age } & $\leq 55$ & $147(74.6 \%)$ \\
\hline & $>55$ & $50(25.4 \%)$ \\
\hline \multirow{2}{*}{ Gender } & Female & $159(80.7 \%)$ \\
\hline & Male & $38(19.3 \%)$ \\
\hline \multirow{3}{*}{ PTC variants } & Conventional & $113(57.4 \%)$ \\
\hline & Follicular & $66(33.5 \%)$ \\
\hline & Oncocytic & $18(9.1 \%)$ \\
\hline \multirow{4}{*}{ T stage } & $\mathrm{T} 1$ & $118(60.1 \%)$ \\
\hline & $\mathrm{T} 2$ & $31(15.7 \%)$ \\
\hline & T3 & $27(13.7 \%)$ \\
\hline & T4 & $21(10.5 \%)$ \\
\hline \multirow{2}{*}{ Tumour size } & Microcarcinoma & $109(55.3 \%)$ \\
\hline & Macrocarcinoma & $88(44.7 \%)$ \\
\hline \multirow{2}{*}{ Necrosis } & Present & $3(1.5 \%)$ \\
\hline & Absent & $194(98.5 \%)$ \\
\hline \multirow{2}{*}{ Calcification } & Present & $89(45.2 \%)$ \\
\hline & Absent & $108(54.8 \%)$ \\
\hline \multirow{2}{*}{ Vascular invasion } & Present & $10(5.1 \%)$ \\
\hline & Absent & $187(94.9 \%)$ \\
\hline \multirow{2}{*}{ Capsule formation } & Present & $89(45.2 \%)$ \\
\hline & Absent & $108(54.8 \%)$ \\
\hline \multirow{2}{*}{$\begin{array}{l}\text { Tumour capsule } \\
\text { invasion }\end{array}$} & Present & $44(22.3 \%)$ \\
\hline & Absent & $153(77.7 \%)$ \\
\hline \multirow{2}{*}{$\begin{array}{l}\text { Thyroid capsule } \\
\text { invasion }\end{array}$} & Present & $40(20.3 \%)$ \\
\hline & Absent & $157(79.7 \%)$ \\
\hline \multirow{2}{*}{$\begin{array}{l}\text { Extrathyroidal } \\
\text { tissue invasion }\end{array}$} & Present & $35(17.7 \%)$ \\
\hline & Absent & $162(82.3 \%)$ \\
\hline \multirow{2}{*}{ Multicentricity } & Present & $33(16.8 \%)$ \\
\hline & Absent & $164(83.2 \%)$ \\
\hline \multirow{2}{*}{$\begin{array}{l}\text { Lymph node } \\
\text { metastasis }\end{array}$} & Present & $15(7.6 \%)$ \\
\hline & Absent & $182(92.4 \%)$ \\
\hline \multirow{5}{*}{$\begin{array}{l}\text { Extratumoural } \\
\text { thyroid tissue* }\end{array}$} & $\begin{array}{l}\text { Lymphocytic } \\
\text { thyroiditis }\end{array}$ & $35(17.8 \%)$ \\
\hline & Diffuse hyperplasia & $60(30.4 \%)$ \\
\hline & Nodular hyperplasia & $39(19.8 \%)$ \\
\hline & $\begin{array}{c}\text { Nodular adenomatous } \\
\text { hyperplasia }\end{array}$ & $48(24.3 \%)$ \\
\hline & $\begin{array}{l}\text { Multinodular } \\
\text { adenomatous } \\
\text { hyperplasia }\end{array}$ & $29(14.7 \%)$ \\
\hline \multirow{2}{*}{ BRAF ${ }^{V 600 E}$} & Wild & $152(77,2 \%)$ \\
\hline & Mutant & $45(22.8 \%)$ \\
\hline \multirow{2}{*}{ lodine exposure } & Short-term & $27(13.7 \%)$ \\
\hline & Long-term & 170 (86.3\%) \\
\hline
\end{tabular}

*One or more condition might have been seen in one extratumoural tissue sample; PTC - papillary thyroid carcinoma 
Table III. Association of BRAF ${ }^{V 600 E}$ mutation with other clinicopathological characteristics

\begin{tabular}{|c|c|c|c|}
\hline & $\begin{array}{l}\text { Wild } \\
\text { n (\%) }\end{array}$ & $\begin{array}{c}\text { Mutant } \\
\text { n (\%) }\end{array}$ & $\mathbf{p}$ \\
\hline Gender & & & 0.318 \\
\hline Female & $125(78.6 \%)$ & $34(21.4 \%)$ & \\
\hline Male & $27(71.1 \%)$ & $11(28.9 \%)$ & \\
\hline PTC variants & & & 0.00002 \\
\hline Conventional & $74(65.5 \%)$ & $39(34.5 \%)$ & \\
\hline Follicular & $63(95.5 \%)$ & $3(4.5 \%)$ & \\
\hline Oncocytic & $15(83.3 \%)$ & $3(16.7 \%)$ & \\
\hline Tumour size & & & 0.183 \\
\hline Microcarcinoma & $88(80.7 \%)$ & $21(19.3 \%)$ & \\
\hline Macrocarcinoma & $64(72.7 \%)$ & $24(27.3 \%)$ & \\
\hline T stage & & & 0.002 \\
\hline $\mathrm{T} 1$ & $100(84.7 \%)$ & $18(15.3 \%)$ & \\
\hline $\mathrm{T} 2$ & $27(87.1 \%)$ & $4(12.9 \%)$ & \\
\hline T3 & $14(51.8 \%)$ & $13(48.2 \%)$ & \\
\hline T4 & $11(52.3 \%)$ & $10(47.7 \%)$ & \\
\hline Vascular invasion & & & 0.036 \\
\hline Present & $5(50.0 \%)$ & $5(50.0 \%)$ & \\
\hline Absent & $147(78.6 \%)$ & $40(21.4)$ & \\
\hline Multicentricity & & & 0.506 \\
\hline Present & $24(72.7 \%)$ & $9(23.7 \%)$ & \\
\hline Absent & $128(78 \%)$ & $36(22 \%)$ & \\
\hline Extrathyroidal extension & & & $<0.00001$ \\
\hline Present & $14(40.0 \%)$ & $21(60.0 \%)$ & \\
\hline Absent & $138(85.2 \%)$ & $24(14.8 \%)$ & \\
\hline Calcification & & & 0.211 \\
\hline Present & $65(73.0 \%)$ & $24(27.0 \%)$ & \\
\hline Absent & $87(80.6 \%)$ & $21(19.4 \%)$ & \\
\hline Thyroid capsule invasion & & & $<0.00001$ \\
\hline Present & $16(40 \%)$ & $24(60 \%)$ & \\
\hline Absent & $136(86.6 \%)$ & $21(13.4 \%)$ & \\
\hline Lymph node metastasis & & & $<0.00001$ \\
\hline Present & $2(13.3 \%)$ & $13(86.7 \%)$ & \\
\hline Absent & $150(82.4 \%)$ & $32(17.6 \%)$ & \\
\hline Age & & & 0.03 \\
\hline$\leq 55$ & $119(81.0 \%)$ & $28(19.0 \%)$ & \\
\hline$>55$ & $33(66.0 \%)$ & $17(34.0 \%)$ & \\
\hline Thyroid background & & & 0.217 \\
\hline Lymphocytic thyroiditis & $28(80.0 \%)$ & $7(20.0 \%)$ & \\
\hline Diffuse hyperplasia & $41(68.3 \%)$ & $19(31.7 \%)$ & \\
\hline Nodular hyperplasia & $30(76.9 \%)$ & $9(21.3 \%)$ & \\
\hline Nodular adenomatous hyperplasia & $42(87.5 \%)$ & $6(12.5 \%)$ & \\
\hline Multinodular adenomatous hyperplasia & $22(75.9 \%)$ & $7(24.1 \%)$ & \\
\hline lodine exposure & & & 0.059 \\
\hline Short-term & $17(63.0 \%)$ & $10(37.0 \%)$ & \\
\hline Long-term & $135(79.4 \%)$ & $35(20.6 \%)$ & \\
\hline
\end{tabular}

PTC — papillary thyroid carcinoma 


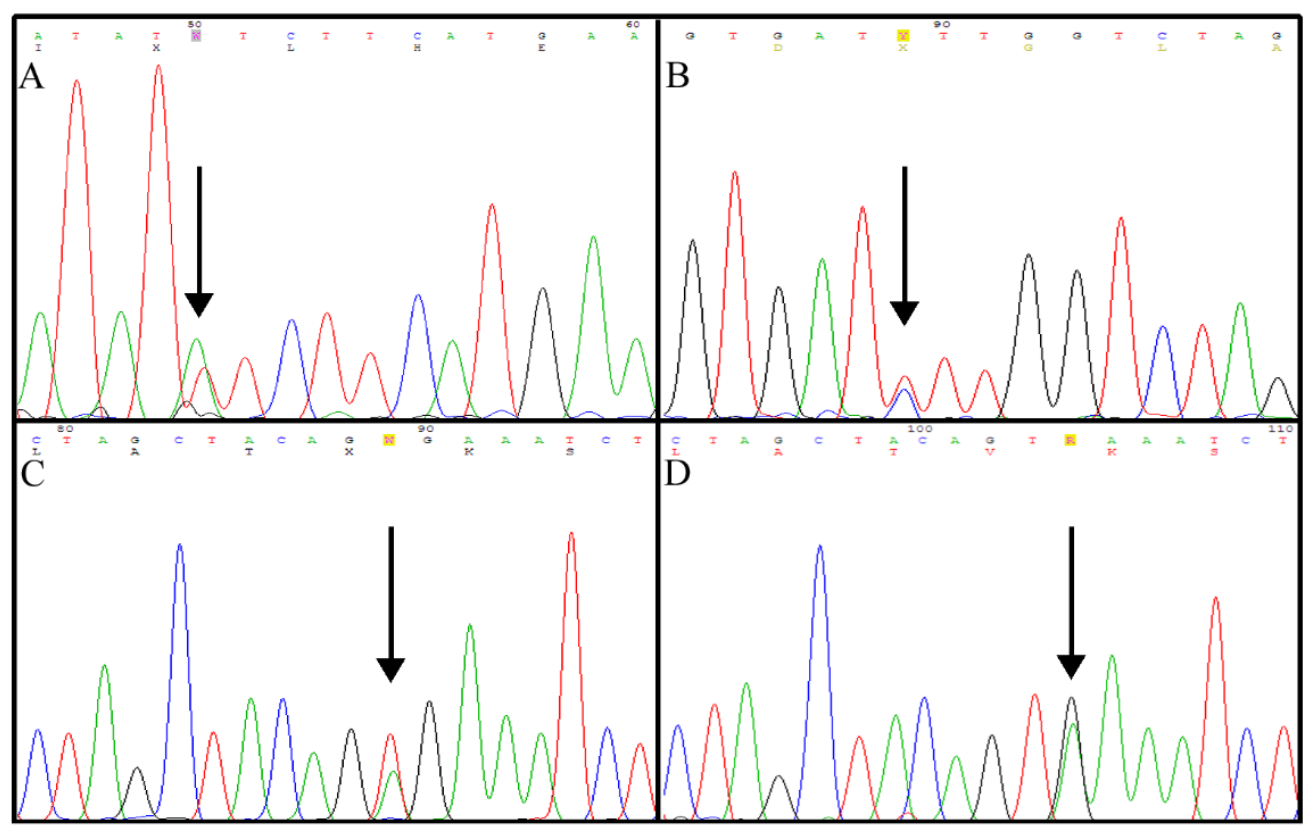

Figure 1. Detected mutations at exon 15 of the BRAF gene. A. $t t t \rightarrow$ tat exchange at codon 583 (BRAF ${ }^{F 583 Y}$ mutation); B. $t t t \rightarrow c t t$ exchange at codon 595 (BRAFF595L mutation); $C$. gtg $\rightarrow$ gag exchange at codon 600 (BRAFV600E mutation); D. gtg $\rightarrow$ gag exchange at codon 600 (BRAF ${ }^{\mathrm{V} 600 \mathrm{~V}}$ mutation). Arrows indicate localisation of the mutations

Table 4. Rare BRAF mutations

\begin{tabular}{|c|c|c|c|c|c|}
\hline BRAF F583Y & Variants of PTC & Tumour size $[\mathrm{cm}]$ & $\begin{array}{l}\text { Thyroid capsule } \\
\text { invasion }\end{array}$ & Soft tissue invasion & $\begin{array}{l}\text { Lymph node } \\
\text { metastasis }\end{array}$ \\
\hline Patient 1 & Conventional & 1.5 & + & + & + \\
\hline Patient 2 & Conventional & 1.4 & + & + & + \\
\hline Patient 3 & Conventional & 1.1 & + & + & + \\
\hline Patient 4 & Conventional & 2.5 & + & + & + \\
\hline \multicolumn{6}{|l|}{ BRAFF595L } \\
\hline Patient 1 & Oncocytic & 3.5 & + & + & - \\
\hline \multicolumn{6}{|l|}{$B R A F^{1600 v}$} \\
\hline Patient 1 & Conventional & 0.6 & - & - & - \\
\hline Patient 2 & Follicular & 3.0 & - & - & - \\
\hline Patient 3 & Oncocytic & 3.5 & + & + & - \\
\hline
\end{tabular}

PTC — papillary thyroid carcinoma

The $B R A F^{F 583 Y}$ was found in four conventional variants of PTC. Tumours with BRAF ${ }^{F 83 Y}$ mutation were macrocarcinomas, all of which had thyroid capsule invasion, soft tissue invasion, and lymph node metastasis. The identified $B R A F^{F 595 L}$ mutation in the oncocytic variant of PTC was a macrocarcinoma with thyroid capsule and soft tissue invasion. Lastly, the $B R A F^{V 600 V}$ mutation was estimated as one in each of the conventional, follicular, and oncocytic variants (Fig. 1). Regarding this mutation arising from three different PTC variants, the conventional one was microcarcinoma whereas follicular and oncocytic variants were noted as macrocar- cinoma (Tab. IV). All these mutations were previously reported, and they were not directly associated with the constitutive activation of the BRAF protein. But it is reported that $B R A F^{{ }^{F 595}}$ mutation is a gain-of-function variant with intermediate activity that does not act paradoxically, but cooperates with mutant RAS to promote oncogenic signalling $[14,15]$.

\section{Discussion}

Papillary thyroid carcinoma is the most frequently encountered malignant thyroid tumour. Although cu- 
rative treatment options for advanced disease are still lacking, rapid progress has been made over the years in understanding the molecular mechanisms underlying PTC tumorigenesis and progression. Among the genetic abnormalities, activating $B R A F^{V 600 E}$ in the mitogen activated protein kinase pathway is the most commonly observed mutation, with a prevalence of $29-83 \%$ [2-5]. In the current study, we evaluated the $B R A F^{V 600 E}$ mutation prevalence and its association with clinicopathological characteristics and a potential environmental causative agent of BRAF V600E, iodine exposure.

The presence of $B R A F^{V 600 E}$ mutation portends a worse prognosis in many series [16-18]. In an analysis of 314 patients, those with a $B R A F^{V 600 E}$ mutation had a significantly worse outcome than did those with a wild-type $B R A F$ [19]. Higher rates of recurrent and persistent disease were observed. Similarly, a recent metanalysis [16] involving 2247 patients found a higher likelihood of recurrent disease in $B R A F^{V 600 E}$-positive patients. A retrospective multicentre study by Xing et al. revealed poorer recurrence-free survival in mutation-positive patients [20]. The impact of $B R A F^{V 600 E}$ mutation on survival could not be addressed in the present study because most of the patients were lost to follow-up.

Despite the scant evidence on survival due to the necessity of longer follow-up time, abundant data is available regarding clinicopathological factors and $B R A F^{V 600 E}$ relation. Xing et al., in their review, reported that $B R A F^{V 600 E}$ was associated with extrathyroidal invasion, lymph node metastasis, and advanced surgical stage [21]. Our findings, in addition to these three parameters that have been confirmed to be poor prognostic by almost all studies, indicate that conventional variant and vascular invasion were positively associated with $B R A F^{V 600 E}$ mutation. The specific histological variant being a high-risk feature was compatible with the results of Lee et al., who reported that $B R A F^{V 600 E}$ mutation was most frequent in tall-cell followed by conventional variant [22]. There were no tall cell variants in the present study. However, follicular and oncocytic variants existed and had lower frequencies of mutation than the conventional variant. In accordance with our findings, Smith et al., in their analysis investigating whether mutation rates differ between conventional versus follicular variant, found that $B R A F^{V 600 E}$ mutation is significantly more common in conventional variant PTC [23]. Another study by Nikiforova et al. came to same conclusion, finding an impact of $B R A F^{V 600 E}$ on the incidence of unfavourable prognostic factors including classic and tall cell variant histology and advanced stage [24]. The authors also noted that older age was correlated with mutation positivity. Likewise, $>45$ years of age at diagnosis was shown to have close association with $B R A F^{V 600 E}$ in the study by Lu et al. [25]. On the other hand, the current study failed to show the same, but, adjusting the cut-off level to 55 years according to the current TNM staging, our results were also consistent with the previous studies. Older age at diagnosis (> $55)$ was correlated with $B R A F^{V 600 E}$ mutation presence.

In a recent study from China, 1032 patients were evaluated. The authors ended up with $54.6 \%$ BRAF ${ }^{V 600 E}$ mutation, which was significantly associated with extrathyroidal extension and advanced TNM stage [7]. They also concluded that thyroid background of Hashimoto thyroiditis (HT) and lymphocytic thyroiditis (LT) were negatively correlated with mutation presence. Lim et al., by a single-centre experience with 3130 cases, reported a similar result, observing that PTC with a background of LT was significantly lower in those with the $B R A F^{V 600 E}$ mutation compared with those with wild-type $B R A F$ [26]. In another study exploring $B R A F^{V 600 E}$ mutation as a predictor for central nodal metastasis, HT emerged as an independent protective factor. In the current study we found no significant association with thyroid background and $B R A F^{V 600 E}$ mutation. However, the frequency of $B R A F^{V 600 E}$ mutation was remarkably low $(22.8 \%)$ compared to both previous reports [27] and the above-mentioned data, in which mutation rates were $54.6 \%, 74.3 \%$, and $75.3 \%$, respectively. The difference might be attributable to the diverse histological variant composition across the studies. The current study involved $34.5 \%$ of follicular variant PTC. A study by Navarro et al., involving a much lower percentage of follicular variants $(4.6 \%)$ than our study, identified a relatively low ratio of $B R A F^{V 600 E}$ mutations (38.4\%) compared to existing literature [28]. Another possible explanation for this could be the heterogeneity in selected populations and the mutation analysis techniques.

In a study conducted in the Irish population, the prevalence of $B R A F^{V 600 E}$ mutation, compared to the RET/ PTC mutation in PTC, was higher than previously, and the authors suspected that this might be due to an environmental factor [29]. At least some data suggest potential association with high iodine intake and $B R A F^{V 600 E}$. The available data are conflicting, with some suggesting positive and others negative or no relation.

In the first study analysing iodine status in Turkey conducted from 1997 through 1999, median urinary iodine concentration of the various regions was noted as $36 \mu \mathrm{g} / \mathrm{L}$; the follow-up study, in 2007 , evaluated the performance of the iodisation of table salt and showed that the median urinary iodine amount increased to $130 \mu \mathrm{g} / \mathrm{L}$. Considering these data as a guide, our study, undertaken between 2000 and 2012, did not address the urinary iodine concentration, but aimed at looking for the impact of "relative increment in iodine exposure" on BRAF mutation. We defined the exposure as the time spent from the iodisation process of table salt in 
our country and dichotomised into short-term and long-term, according to whether the PTC was diagnosed in the first or second half of the study period. The trials had different designs on defining iodine exposure. In one study, the authors compared the prevalence of the BRAF ${ }^{V 600 E}$ mutation in classical PTC of 1032 patients from five regions in China that harbour different iodine content in natural drinking water [7]. They argued that high iodine intake may be a risk factor for PTC because the prevalence of $B R A F^{V 600 E}$ mutation was significantly higher in regions with high iodine content than any of the regions with normal iodine content. Contrary to this finding, in the present study, there was no significant association between long-term iodine exposure and $B R A F^{V 600 E}$. However, the iodine content of drinking water in the previous trial was far above the amount used for prophylaxis in table salt. Additionally, the authors speculated that the worldwide increment in the frequency of PTC is the consequence of rising iodine support, but this should be interpreted cautiously. More extensive utility of thyroid ultrasonography and fine-needle aspiration biopsy compared to previous years may have an effect on the rise in incidence. In support of this, we experienced far more PTC cases in the second half of our study period.

On the other hand, investigators at Harvard Medical School noted that, on exposure with excess iodine, rat thyroid follicular cells that conditionally express $B R A F^{V 600 E}$ showed a decrease in $B R A F^{V 600 E}$-induced up-regulation of miR-17-92, blocking NOTCH signalling, which confers proliferative advantage. Overall, this study shows that high iodine exerts a protective influence overBRAF ${ }^{V 600 E}$-activated thyroid cells. Iodine might reduce acute $B R A F^{V 600 E}$ oncogene induction and activity [30]. Frasca et al. recently examined the relationship of $B R A F^{V 600 E}$ mutation in PTC with iodine intake in some regions in Italy. The authors found $B R A F^{V 600 E} \mathrm{mu}-$ tation in 107 of 270 cases in an iodine-sufficient region (40\%) vs. 18 of 53 cases of PTC in an iodine-deficient region (34\%), which was, similarly to our study, statistically insignificant [31].

This study had some features that might be viewed as potential weaknesses. First, selection bias might have been introduced due to the retrospective nature of the study. Second, follow-up data do not exist, thus we are unable to comment on whether the findings translate into outcome measures. Lastly, the sample size is small.

\section{Conclusion}

The results of our retrospective study provide evidence suggesting that $B R A F^{V 600 E}$ mutation is correlated with unfavourable prognostic features. The results also challenge existing assumptions about the high iodine exposure and $B R A F$ mutation incidence, demonstrating no association.

\section{Acknowledgements}

This work was supported by a grant of the Research Fund of the Tekirdağ Namık Kemal University (Project number: NKUBAP.01.YL.16.021).

\section{References}

1. Hundahl SA, Fleming ID, Fremgen AM, et al. A National Cancer Data Base report on 53,856 cases of thyroid carcinoma treated in the U.S., 1985-1995. Cancer. 1998; 83(12): 2638-2648, indexed in Pubmed: 9874472.

2. Tallini G, Asa SL. RET oncogene activation in papillary thyroid carcinoma. Adv Anat Pathol. 2001; 8(6):345-354, indexed in Pubmed: 11707626.

3. Davies H, Bignell GR, Cox C, et al. Mutations of the BRAF gene in human cancer. Nature. 2002; 417(6892): 949-954, doi: 10.1038/nature00766, indexed in Pubmed: 12068308

4. Cohen $Y$, Xing M, Mambo E, et al. BRAF mutation in papillary thyroid carcinoma. J Natl Cancer Inst. 2003; 95(8): 625-627, doi: 10.1093/jnci/95.8.625 indexed in Pubmed: 12697856.

5. Xu X, Quiros RM, Gattuso P, et al. High prevalence of BRAF gene mutation in papillary thyroid carcinomas and thyroid tumor cell lines. Cancer Res. 2003; 63(15): 4561-4567, indexed in Pubmed: 12907632.

6. Suzuki K, Mitsutake N, Saenko V, et al. Radiation signatures in childhood thyroid cancers after the Chernobyl accident: possible roles of radiation in carcinogenesis. Cancer Sci. 2015; 106(2): 127-133, doi: 10.1111/cas.12583, indexed in Pubmed: 25483826.

7. Guan H, Ji M, Bao R, et al. Association of high iodine intake with the T1799A BRAF mutation in papillary thyroid cancer. J Clin Endocrinol Metab. 2009; 94(5): 1612-1617, doi: 10.1210/jc.2008-2390, indexed in Pubmed: 19190105.

8. Erdoğan G, Erdogan MF, Emral R. Iodine status and goiter prevalence in Turkey before mandatory iodinization. J Endocrinol Invest. 2002; 25(3): 224-228, doi: 10.1007/BF03343994, indexed in Pubmed: 11936463

9. Erdoğan MF, Ağbaht K, Altunsu T, et al. Current iodine status in Turkey. J Endocrinol Invest. 2009; 32(7): 617-622, doi: 10.1007/BF03346519, indexed in Pubmed: 19564718.

10. Hacettepe University Instute of Population Studies Ministry of Health Turkey Demographic and Health Survey Iodization of table salts. Turkey, Ankara 2003: 145-147.

11. Gozu HI, Bircan R, Krohn K, et al. Similar prevalence of somatic TSH receptor and Gsalpha mutations in toxic thyroid nodules in geographical regions with different iodine supply in Turkey. Eur J Endocrinol. 2006; 155(4): 535-545, doi: 10.1530/eje.1.02253, indexed in Pubmed: 16990652

12. Qu K, Pan Q, Zhang Xi, et al. Detection of BRAF V600 mutations in metastatic melanoma: comparison of the Cobas 4800 and Sanger sequencing assays. J Mol Diagn. 2013; 15(6): 790-795, doi: 10.1016/j. moldx.2013.07.003, indexed in Pubmed: 23994118.

13. Rosenthal A, Coutelle O, Craxton M. Large-scale production of DNA sequencing templates by microtitre format PCR. Nucleic Acids Res. 1993; 21(1): 173-174, doi: 10.1093/nar/21.1.173, indexed in Pubmed: 8441614.

14. Kordes M, Röring M, Heining C, et al. Cooperation of BRAF(F595L) and mutant HRAS in histiocytic sarcoma provides new insights into oncogenic BRAF signaling. Leukemia. 2016; 30(4): 937-946, doi: 10.1038/leu.2015.319, indexed in Pubmed: 26582644

15. Park JiH, Kwon HJu, Park CS, et al. Anaplastic Transformation of Papillary Thyroid Carcinoma in a Young Man: A Case Study with Immunohistochemical and BRAF Analysis. Korean J Pathol. 2014; 48(3): 234-240, doi: 10.4132/KoreanJPathol.2014.48.3.234, indexed in Pubmed: 25013423.

16. Russo M, Malandrino P, Nicolosi ML, et al. The BRAF(V600E) mutation influences the short- and medium-term outcomes of classic papillary thyroid cancer, but is not an independent predictor of unfavorable outcome. Thyroid. 2014; 24(8): 1267-1274, doi: 10.1089/thy.2013.0675, indexed in Pubmed: 24787545

17. Guerra A, Fugazzola L, Marotta V, et al. A high percentage of BRAFV600E alleles in papillary thyroid carcinoma predicts a poorer outcome. J Clin Endocrinol Metab. 2012; 97(7): 2333-2340, doi: 10.1210/jc.2011-3106, indexed in Pubmed: 22508706.

18. Xing M, Alzahrani AS, Carson KA, et al. Association between BRAF V600E mutation and mortality in patients with papillary thyroid cancer. JAMA. 2013; 309(14): 1493-1501, doi: 10.1001/jama.2013.3190, indexed in Pubmed: 23571588

19. Kebebew E, Weng J, Bauer J, et al. The prevalence and prognostic value of BRAF mutation in thyroid cancer. Ann Surg. 2007; 246(3): 466-70; discussion 470, doi: 10.1097/SLA.0b013e318148563d, indexed in Pubmed: 17717450. 
20. Chen $Y$, Sadow PM, Suh $H$, et al. BRAF(V600E) Is Correlated with Recurrence of Papillary Thyroid Microcarcinoma: A Systematic Review, Multi-Institutional Primary Data Analysis, and Meta-Analysis. Thyroid. 2016; 26(2): 248-255, doi: 10.1089/thy.2015.0391, indexed in Pubmed: 26671072.

21. Xing M, Alzahrani AS, Carson KA, et al. Association between BRAF V600E mutation and recurrence of papillary thyroid cancer. J Clin Oncol. 2015; 33(1): 42-50, doi: 10.1200/JCO.2014.56.8253, indexed in Pubmed: 25332244.

22. Lee JH, Lee ES, Kim YS. Clinicopathologic significance of BRAF V600E mutation in papillary carcinomas of the thyroid: a meta-analysis. Cancer. 2007; 110(1): 38-46, doi: 10.1002/cncr.22754, indexed in Pubmed: 17520704.

23. Smith RA, Salajegheh A, Weinstein S, et al. Correlation between BRAF mutation and the clinicopathological parameters in papillary thyroid carcinoma with particular reference to follicular variant. Hum Pathol. 2011; 42(4): 500-506, doi: 10.1016/j.humpath.2009.09.023, indexed in Pubmed: 21167555.

24. Nikiforova MN, Kimura ET, Gandhi M, et al. BRAF mutations in thyroid tumors are restricted to papillary carcinomas and anaplastic or poorly differentiated carcinomas arising from papillary carcinomas. J Clin Endocrinol Metab. 2003; 88(11): 5399-5404, doi: 10.1210/jc.2003-030838, indexed in Pubmed: 14602780.

25. Lu H, Qiu T, Ying J, et al. [Correlation between BRAF V600E mutation and clinicopathologic features of papillary thyroid carcinoma].
Zhonghua Bing Li Xue Za Zhi. 2014; 43(12): 794-798, indexed in Pubmed: 25623974.

26. Lim JY, Hong SW, Lee YS, et al. Clinicopathologic implications of the BRAF(V600E) mutation in papillary thyroid cancer: a subgroup analysis of 3130 cases in a single center. Thyroid. 2013; 23(11): 1423-1430, doi: 10.1089/thy.2013.0036, indexed in Pubmed: 23496275.

27. Lang BH, Chai YJ, Cowling BJ, et al. Is BRAFV600E mutation a marker for central nodal metastasis in small papillary thyroid carcinoma? Endocr Relat Cancer. 2014; 21(2): 285-295, doi: 10.1530/ERC-13-0291, indexed in Pubmed: 24402044

28. Navarro-Locsin CG, Chang AMV, Daroy ML, et al. Clinical and histopathological profile of BRAF V600E mutation in conventional papillary thyroid carcinoma in a Filipino population. Malays J Pathol. 2016; 38(2): 141-148, indexed in Pubmed: 27568671.

29. Smyth P, Finn S, Cahill S, et al. ret/PTC and BRAF act as distinct molecular, time-dependant triggers in a sporadic Irish cohort of papillary thyroid carcinoma. Int J Surg Pathol. 2005; 13(1): 1-8, doi: 10.1177/10668969050 1300101, indexed in Pubmed: 15735849.

30. Daniell K, Nucera C. Effect of the micronutrient iodine in thyroid carcinoma angiogenesis. Aging (Albany NY). 2016; 8(12): 3180-3184 doi: 10.18632/aging.101143, indexed in Pubmed: 27997357.

31. Frasca F, Nucera C, Pellegriti G, et al. BRAF(V600E) mutation and the biology of papillary thyroid cancer. Endocr Relat Cancer. 2008; 15(1): 191-205, doi: 10.1677/ERC-07-0212, indexed in Pubmed: 18310287. 